\title{
DOA BATIN: DOA PERSAHABATAN DENGAN YESUS MENURUT SANTA TERESIA DARI YESUS
}

Berthold Anton Pareira

\begin{abstract}
This is a short study of mental prayer according to St.Teresa of Jesus, doctor of the Church.Mental prayer according to her 'is nothing else than an intimate sharing between friends to be alone with Him who we know loves us'. This definition is biblical and ahead of Dei Verbum,art.2. God is our friend. Mental Prayer has to be the soul of vocal prayer. Both are closely related as appear in the teaching of Jesus on the persistence of prayer (Lk 11:1-4,5-8,9-13).
\end{abstract}

Keywords: mental prayer, friends, love, to be alone, vocal prayer.

\section{Abstrak}

Studi ini memperdalam definisi doa batin menurut St.Teresia dari Yesus sebagai tidak lain dari suatu pergaulan sebagai sahabat dengan Sang Sahabat yang mencintai kita. Definisi ini mendahului Dei Verbum, art.2 tentang tujuan pewahyuan diri Allah. Menurut Teresia pula doa batin dan doa vokal tak terpisahkan satu sama lain. Kita dapat melihat hal itu pula dari penjelasan Yesus tentang doa Bapa Kami (Luk 11:1-4,5-8,9-13).

Kata kunci: doa batin, sahabat, cinta, sendiri, doa lisan

\section{Pengantar}

Tema hari studi kita ini ialah tentang persahabatan dan saya mengingat akan apa yang dikatakan St.Teresia dari Yesus (1515-1582), guru doa, tentang doa batin. Menulis tentang doa sama dengan menulis tentang seluruh kehidupan manusia: apakah doa itu, bagaimana harus berdoa, apa hubungan 
doa dengan cinta kasih, doa dan kerendahan hati, doa dan penyangkalan diri, sampai ke mana orang harus berdoa dan masih banyak lagi yang tidak dapat saya sebutkan satu per satu di sini. Temanya seluas kehidupan manusia yang beriman kepada Yesus Kristus. St. Teresia sendiri menulis tiga buku besar tentang doa yakni Vida, Camino dan Las Moradas ${ }^{1}$ dan praktis seluruhnya berdasarkan pengalamannya sebagai seorang beriman yang berjuang untuk maju dalam hidup doa. Dan betapa besar pengalamannya! Dalam tulisan ini saya akan memperdalam apa yang dikatakannya tentang doa batin.

\section{Apakah Doa Batin Itu?}

Doa batin atau doa hening bagi Teresia "tidaklah lain dari pergaulan sebagai sahabat yang kerap kita lakukan secara sendirian dengan seorang Sahabat yang mencintai kita yakni dengan Tuhan Yesus. (Vida 8:5). Tuhan Yesus adalah sahabat kita. Dia telah mencintai kita lebih dahulu.

Tuhan Yesus adalah pusat hidup doa Teresia (Vida 12 dan 22; Camino 26:1). Dia adalah sahabat yang baik dan setia. Itulah pengalamannya. Ketika mengalami tantangan dan pencobaan, Teresia selalu memandang kepada Yesus yang menderita karena dosa-dosa kita dan mengalami bahwa Yesus adalah sahabat. Tuhan Yesus selalu menolong dan memperhatikan orang yang mengangkat matanya kepada-Nya (Vida 22:6). Dia adalah teladan kita yang paling baik. Apalagi yang dapat kita rindukan daripada mendapatkan Dia berada di samping kita? (Vida 22:7). Setiap kali kita mengingat Kristus, kita hendaknya mengingat kasih-Nya yang begitu luar biasa kepada kita. Kalau kita mengingat kasih-Nya, kita juga akan digerakkan untuk mengasihiNya. Kasih melahirkan kasih (Vida 22:14: "amor saca amor").

Kristus yang menjadi pusat doanya dikenalnya lewat Injil. Menurut

1 Tentang ketiga buku ini, bdk Berthold Anton Pareira, "St.Teresa of Jesus: The Woman Theologian," Studia Philosophica et Theologica, Vol.18 No.1 Maret 2018, 1-16. Saya menggunakan terbitan baik asli dalam bahasa Spanyol maupun terjemahannya dalam bahasa Inggris. 
Teresia orang yang terus menerus memandang kepada Kristus akan mengenal dirinya sendiri (Moradas I 2:9). Siapa yang belum melihat pentingnya doa, dia harus memandang Kristus dengan penuh iman dan belajar dari-Nya.

Baiklah sekarang kita melihat apa yang dikatakan Teresia dari Yesus tentang doa batin. Apa yang kita lihat dari definisi doa batin di atas? Pertama, Teresia mengawali definisinya dengan pernyataan "tidaklah lain". Apa maksudnya? Tidaklah mudah menafsirkannya. Akan tetapi, dari ajarannya tentang doa dan dari definisi ini kita dapat mengatakan bahwa doa batin itu bukan soal banyak berpikir, melainkan banyak mencinta". Doanya digerakkan oleh kerinduan untuk berkembang dalam cinta, hidup sesuai dengan kehendak Tuhan, hidup sesuai dengan firman Tuhan (Moradas IV 1:7; Foundations/Las Fundaciones ${ }^{2}$ 5:2). Persahabatan itu hanya bisa sejati dan bertahan kalau kehendak mereka sesuai satu sama lain.Kepada Tuhan hati kita berkata: "Jadilah kehendak-Mu". Kehendak Tuhan adalah kehendak keselamatan, kehendak kasih. Kita harus mau hidup sesuai dengan kehendak keselamatan ini. Baru atas cara itu persahabatan kita dengan Tuhan Yesus menjadi makin mendalam dan mengembangkan kasih kita (Vida 8:5).

Dengan demikian doa adalah tindakan cinta. Kita datang dengan penuh cinta kepada Dia yang mengasihi kita lebih dahulu. Kita percaya akan kasih-Nya! Bagaimana kasih-Nya kepada kita? Sangat besar dan luar biasa kepada kita hanya kita tidak menyadarinya dan kerap mengingatnya. Karena cinta-Nya yang besar Dia telah mengajarkan doa Bapa Kami kepada kita (Camino 26:1). Kita perlu ingat hal ini dengan baik.

Kita harus mencari tempat dan waktu agar berada sendiriandengan Tuhan. Sahabat yang baik mencari waktu dan tempat untuk berjumpa dan bercakap-cakap dengan sahabatnya. Persahabatan itu hilang apabila tidak ada komunikasi. Bagaimana kita bisa mengenal Tuhan kalau kita jarang berkomunikasi dengan-Nya? Orang yang jarang berkomunikasi

\footnotetext{
2 Buku yang mengisahkan tentang perjuangan Teresia mendirikan biara-biara kontemplatif untuk para suster. Perempuan kontemplatif besar ini mendirikan 17 biara!
} 
menjadi asing satu sama lain. Hal ini terjadi bahkan dalam keluarga (bdk Camino 26:9). Kita harus kerap bergaul sendirian dengan Tuhan Yesus, sahabat kita.

Ajarannya ini berdasarkan pengalamannya sendiri.Dia suka mencari persahabatan.Dia selalu mengingat orang yang suka kepadanya dan yang dia sukai.Akan tetapi, setelah keindahan Kristus dinyatakan kepadanya, maka keindahan yang lain tidak punya arti lagi baginya. Dia hanya mau mencintai Yesus Kristus dan mencari pesahabatan hanya dengan-Nya (Vida 37:4). ${ }^{3}$ Allah telah mencintai kita lebih dahulu dan puncaknya terjadi di dalam Kristus.

Dalam uraiannya ini Teresia tidak menyebut secara eksplisit Yoh 15:15.Tuhan Yesus menyebut kita sahabat karena segala sesuatu yang didengar-Nya dari Bapa-Nya telah diberitahukan-Nya kepada kita (Yoh 15:15).

Tempat doa ialah hati manusia(bdk Mat 6:6). Di sanalah Tuhan bersemayam. Dalam hubungan dengan hal ini Teresia berbicara tentang doa recogimiento $=$ rekoleksi $=$ pengheningan $=$ khusyu $($ Camino 26;2829; Moradas 4:3). Kita dapat menerjemahkannya dengan doa pemusatan atau doa kerinduan. Kerinduan kepada Allah yang bersemayam di dalam hati kita harus menjadi gerakan kita datang kepada-Nya.Cinta mendorong kita datang kepada-Nya.

\section{Dari Tujuan Wahyu Allah ke Doa Batin Teresia}

Ajaran Teresia tentang doa batin ini sesuai betul dengan pernyataan konstitusi dogmatis Dei Verbum, art, 2 dari Konsili Vatikan II tentang tujuan wahyu Allah. Dalam Bab I tentang Wahyu Konsili Vatikan II berbicara tentang hakikat dan objek wahyu. Apa yang dikatakan tentang hakikat wahyu itu sungguh padat, mendalam dan sangat bagus. Konsili berbicara tentang Wahyu bukan dalam bahasa ilmiah atau otak, melainkan dalam bahasa yang punya rasa dan langsung berhubungan dengan kehidupan manusia. Tuhan

3 Bdk Chiara Vasciaveo,"Teresa di Gesu la scoperta del Dio Amico," Horeb 15/V(1996/n.3),8996. 
Allah mewahyukan diri-Nya supaya kita mengenal Dia dengan benar, mengasihi Dia dan mengambil bagian dalam kehidupan-Nya. Caranya Dia menyatakan diri ialah berbicara sebagai sahabat, akrab, dekat dan penuh kasih. Manakah uraian yang lebih dapat ditangkap dan dirasakan lebih daripada uraian ini? Saya rasakan keindahannya.

Dalam kebaikan dan kebijaksanaan-Nya Allah berkenan mewahyukan diri-Nya dan rencana keselamatan-Nya. Melalui Kristus, Sabda yang menjadi manusia dan dalam kekuatan Roh Kudus kita mencapai Bapa dan mengambil bagian dalam hakikat ilahi-Nya. Dengan pewahyuan ini Allah yang tak kelihatan dalam kasih-Nya yang besar berbicara kepada manusia seperti kepada sahabat dan bergaul dengan mereka untuk mengundang dan memasukkan mereka dalam persekutuan dengan-Nya.

Dalam uraian ini konsili mengutip atau menunjuk dua teks penting satu dari Perjanjian Lama yang berbunyi: "Dan TUHAN berbicara kepada Musa dengan berhadapan muka seperti seorang berbicara dengan temannya" (Kel 33:11) dan satu lagi dari Perjanjian Baru yang berbunyi: "Kamu adalah sahabat-Ku, jikalau kamu melakukan apa yang Kuperintahkan kepadamu. Aku tidak menyebut kamu lagi hamba, sebab hamba tidak tahu apa yang diperbuat oleh tuannya, tetapi Aku menyebut kamu sahabat karena Aku telah memberitahukan kepada kamu segala sesuatu yang telah Kudengar dari Bapa-Ku” (Yoh 15:14-15).

Lalu bagaimana tujuan wahyu Allah ini dapat diwujudkan? Dengan doa dan hal itu akan segera kita lihat di bawah ini.

\section{Doa dan Persahabatan (Luk 11:5-8,9-13)}

Tuhan Yesus adalah perwujudan dari persatuan-Nya yang mesra dengan Bapa-Nya di surga. Berulang-ulang Injil menyaksikan hal itu. Kesaksian tentang hubungan-Nya yang begitu mesra dengan Bapa-Nya di surga inilah yang membuat seorang murid meminta kepada-Nya agar mereka diajarkan berdoa. Lalu Tuhan Yesus mengajarkan doa Bapa Kami kepada kita murid-murid-Nya (Luk 11:1-4).

Pengajaran tentang doa Bapa Kami ini lalu disusul dengan suatu perumpamaan (Luk 11:5-8) dan penjelasan lanjutan (Luk 11:9-13). Kita harus 
berdoa dengan tekun dan tanpa malu seperti yang terjadi antara sahabat yang baik (Luk 11:5-8; bdk 18:-8). Tengah malam seorang sahabat mendatangi sahabatnya. Dia mendapat tamu yang juga adalah sahabatnya, tetapi dia tidak punya apa-apa untuk menjamu tamunya itu. Dia lalu pergi kepada sahabatnya yang lain yang sudah tidur. Kepercayaannya yang luar biasa kepada sahabatnya ini membuat dia datang dan mendesak supaya diberikan roti kepadanya untuk menjamu tamunya. Desakan tanpa malu orang ini membuat sahabatnya itu bangun dan mengabulkan permintaannya.

Bapa kita di surga (11:1-4,13) juga akan berbuat demikian kalau kita datang mendekati-Nya sebagai sahabat. Dia tidak punya jam tidur. Dia selalu siap sedia untuk mendengarkan orang yang datang kepada-Nya sebagai kepada sahabat yang baik.

Sahabat kita yang baik itu adalah Bapa kita yang di surga (11:9-13). Dia bahkan akan memberikan lebih daripada yang kita minta. Dia akan memberikan Roh Kudus kepada orang yang dengan tekun meminta, mencari dan mengetuk.

\section{Hubungan antara Doa Lisan dan Doa Batin}

Allah berbicara kepada manusia sebagai sahabat dan manusia menjawabnya harus juga sebagai sahabat. Hanya lewat doa batin? Sama sekali tidak! Allah berbicara kepada kita sebagai sahabat juga melalui doa vokal khususnya doa Gereja yang praktis seluruhnya dijiwai oleh Kitab Suci. Mari kita dengarkan Teresia tentang hal doa vokal.

Teresia membedakan doa lisan dan doa batin, tetapi keduanya berhubungan. Doa lisan ialah bahan doa yang telah jadi seperti doa Bapa Kami, Mazmur, Ibadat Waktu/Harian dan puncaknya lewat perayaan Ekaristi.

Doa lisan yang diuraikannya dengan panjang lebar ialah doa Bapa Kami (Camino 27-42). Doa ini adalah doa Tuhan sendiri. Doa lisan didoakan dengan diucapkan.Doa ini hanya bisa dilakukan dengan baik apabila orang mengerti apa yang didoakan dan mendoakannya dengan penuh perhatian dan iman.Kita harus tahu apa yang kita ucapkan, dengan siapa kita berbicara dan siapakah kita (bdk Camino 25:3). Sebagai seorang guru 
yang baik Teresia berulang-ulang menekankan hal itu (Camino 22:7;42:3) Sikap kita akan berubah kalau kita memperhatikan hal itu (Camino 22:2-3). Lewat doa lisan orang bisa mencapai kontemplasi (Camino 30:7). Teresia menulis buku Camino/The Way of Perfection hanya untuk menerangkan doa Bapa Kami bagi orang-orang yang tidak bisa melakukan doa batin dan bahwa dengan doa ini orang bisa mencapai kontemplasi. Sungguh dalam apa yang ditulis Teresia dalam bab-bab ini.

Persyaratan yang sama harus dikenakan pada doa Gereja yakni Ibadat Harian (Camino 22:3). Doa ini bersifat adorasi dan memupuk sikap kontemplatif. Ajakan untuk menyembah Tuhan sudah langsung terdengar sejak pembukaannya. Adorasi ini dinyatakan setiap kali pada bait terakhir Madah dan pernyataan Kemuliaan kepada Tritunggal Mahakudus yang didoakan paling kurang 20 kali dalam seluruh ibadat ini.

Mazmur karena seni perulangan dan kaya akan penggunaan kiasan sangat kuat memupuk sikap kontemplatif. Dia memiliki citarasa yang sangat mendalam tentang Allah yang hidup. Allah yang kita jumpai dalam mazmur bukanlah Allah yang jauh, melainkan Allah yang dekat.Kata-katanya penuh daya sehingga membuat orang yang mengatakannya menemukan pengalamannya sendiri. St. Agustinus berbicara dengan Tuhan tentang hidupnya dalam buku Confesionesnya sebagian besar menggunakan katakata Mazmur.

Banyak yang sudah mulai mendoakan Ibadat Harian, tetapi kerap tidak tahu mendoakannya dengan baik.Orang tidak mengerti apa yang didoakannya dan berdoa dengan berlari. Orang bukan mendoakan mazmur,melainkan hanya menghabiskannya.Sayang, bahan doa yang istimewa ini tidak lagi menjadi sekolah doa yang mengantar orang kepada Tuhan.

Teresia punya devosi besar pada Ekaristi (Vida 6:6). Ekaristi sebagai suatu perayaan adalah perayaan doa.Praktis seluruhnya dijiwai oleh Kitab Suci.Inilah puncak Allah mau menjalin persahabatan dengan manusia. Liturgi Sabda misalnya adalah suatu perayaan kehadiran Tuhan yang bersabda. Seluruhnya dirayakan dalam sikap doa.Tuhan Yesus sendiri hadir dan berbicara dengan kita. Ada perayaanyang sangat indah dan menyentuh. 
Gereja merayakan kehadiran Kristus yang berbicara. Dia bersabda dan manusia (Gereja) menjawab. Itulah doa. Refren mazmur tanggapan mendidik orang kepada doa. Dari sebab itu, kita perlu benar-benar belajar berdoa dalam perayaan ini. Siapa yang tahu berdoa dalam Liturgi Sabda ini, dia juga akan tahu merayakan Ekaristi dengan baik.Mazmur tanggapan mengajar kita untuk belajar berdoa menanggapi Sabda Allah.

Kita harus berdoa dengan penuh perhatian dan dengan cinta. Itulah kunci dari sikap doa Teresia.Membaca Kitab Suci dengan tenang dan penuh perhatian adalah langkah pertama ke doa.Bacaan itu akan membangkitkan doa.Jika kita tidak tahu bagaimana harus berdoa,maka hal pertama yang harus dilakukan ialah membaca Kitab Suci khususnya Injil dengan tenang dan penuh perhatian. Seluruh pembacaan dalam sikap demikian adalah suatu doa. Teresia biasa melakukan hal itu(Camino 26:34,10).

Bacaan dan doa semacam ini akan membawa kita kepada kontemplasi. Tuhan akan menerangi pikiran dan hati kita serta memberi kekuatan dan ketertarikan kita kepada-Nya. Kita akan mengalami bahwa Tuhan adalah sahabat kita yang mahabaik.

Kitab Suci menduduki tempat yang sentral dalam hidup doa Teresia. Dia mengingat banyak peristiwa Kitab Suci dan biasa merenungkannya. Hal itu tampak dengan jelas sekali dari contoh-contoh yang diberikan. Peristiwa-peristiwa yang direnungkannya itu mengantar dia untuk berpikir tentang Allah dan mengasihi-Nya. Renungan ini menjadi kehidupannya dan Teresia berdoa dari peristiwa yang direnungkannya. Dia memandang peristiwa-peristiwa itu dengan hati. Hal ini biasa dilakukan oleh pendoapendoa besar. Mereka menaburkan benih sabda itu dalam hatinya dan menyiramnya berulang-ulang dengan renungannya. Mereka hidup seperti Bunda Maria.

Teresia mencapai puncak kontemplasi sebagaimana yang dianugerahkan Allah kepadanya bukan tanpa perjuangan yang panjang dan tantangan. Hal ini perlu kita perhatikan dengan baik untuk memahami ajarannya. Dia adalah seorang guru doa yang mengajar berdasarkan pengalaman, pertama dari perjuangannya sendiri dan kedua,dari 
pengalamannya menghadapi orang yang punya kesukaran dalam doa yakni suster-suster bimbingannya.

Seluruh tulisan Teresia praktis berbicara tentang doa dan membawa orang kepada doa. Doa sepertinya mengalir begitu saja dalam tulisannya. Dia mengajar, menyampaikan pengalamannya dan berdoa. Teresia menulis dari pengalaman yakni dari perjuangannya untuk menghayati hidup doa. Tulisan-tulisan Teresia dapat dikatakan suatu pendidikan ke hidup doa. Dia mendidik kita berdoa lewat tulisannya. Membaca tulisan-tulisan Teresia berati membaca tulisan seorang yang mencari persahabatan yang mendalam dengan Tuhan.

Orang yang mau maju dalam hidup rohani harus punya kemauan untuk berdoa (Camino 21:2). Allah memberi lebih banyak dari apa yang kita minta, daripada apa yang kita rindukan (Camino 23:6). Pernyataan ini tidak baru karena sudah terdapat dalam Kitab Suci sendiri (bdk. Ef 3:20). Pernyataannya ini sesuai betul dengan Injil (bdk. Luk 11:9-13).

Tulisannya menunjukkan bagaimana dia berdoa. Dia belajar dan berjuang untuk berdoa dengan baik (Vida $1-9) .{ }^{4}$ Kita dapat belajar banyak dari Guru doa ini.

\section{Penutup}

Tema tulisan ini ialah tentang doa batin menurut St.Teresia dari Yesus. Menurut doktor doa ini doa batin ialah doa yang mau membangun persahabatan yang mendalam dengan Tuhan Yesus yang mengasihi kita. Pernyataan ini sesuai betul dengan tujuan pewahyuan Allah dalam Kristus dan dengan ajaran-Nya tentang doa Bapa Kami. Inilah puncak persahabatan yang mau dikerjakan Allah bagi manusia, inilah panggilan yang terdalam dari manusia. Tuhan adalah Allah sahabat! Sekiranya kita memahami sungguh-sungguh-sungguh tujuan pewahyuan Allah ini kita pasti akan berbuah

4 Bdk Berthold Anton Pareira, "Otobigrafi Teresia dari Yesus:Kisah Kerahiman Allah," dlm.Gregorius Pasi-Peter B.Sarbini (ed.) Dosa dan Pengampunan: Pergulatan Manusia dengan Allah (Seri Filsafat Teologi Widya Sasana, vol.26 no.Seri 25; Malang:STFT Widya Sasana, 2016), 207-219. 
banyak bagi hidup dunia. Para kudus telah menyaksikan hal itu dan St.Teresia dari Yesus telah membuktikannya secara amat mengesankan dalam hidupnya. Kontemplasi dan kerasulan tak terpisahkan satu sama lain. (Malang, 1 September 2020). 